2009-02-01

\title{
SWCNT Suppress Inflammatory Mediator Responses in Human Lung Epithelium in Vitro
}

\author{
Eva Herzog \\ Technological University Dublin, eva.herzog@tudublin.ie \\ Hugh Byrne \\ Technological University Dublin, hugh.byrne@tudublin.ie \\ Maria Davoren \\ Technological University Dublin, Maria.davoren@tudublin.ie
}

See next page for additional authors

Follow this and additional works at: https://arrow.tudublin.ie/radart

Part of the Biological and Chemical Physics Commons

\section{Recommended Citation}

Herzog, Eva et al (2009) SWCNT suppress inflammatory mediator responses in human lung epithelium in vitro. Toxicology and Applied Pharmacology, Vol.234, pp.378-390. doi:10.1016/j.taap.2008.10.015

This Article is brought to you for free and open access by the Radiation and Environmental Science Centre at ARROW@TU Dublin. It has been accepted for inclusion in Articles by an authorized administrator of ARROW@TU Dublin. For more information, please contact arrow.admin@tudublin.ie, aisling.coyne@tudublin.ie, gerard.connolly@tudublin.ie.

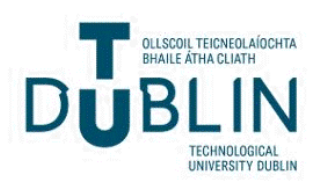




\section{Authors}

Eva Herzog, Hugh Byrne, Maria Davoren, Anke-Gabriele Lenz, Albert Duschl, and Gertie Janneke Oostingh

This article is available at ARROW@TU Dublin: https://arrow.tudublin.ie/radart/8 
SWCNT suppress inflammatory mediator responses in human lung epithelium in vitro

\author{
Eva Herzog $^{{ }^{*}}$, Hugh J. Byrne ${ }^{2}$, Alan Casey ${ }^{2}$, Maria Davoren ${ }^{1}$, Anke-Gabriele Lenz ${ }^{3}$, \\ Konrad L. Maier ${ }^{3}$, Albert Duschl ${ }^{4}$, Gertie Janneke Oostingh ${ }^{4}$
}

${ }^{1}$ Radiation and Environmental Science Centre (RESC), Focas Institute, Dublin Institute of
Technology, Kevin Street, Dublin 8, Ireland, , Telephone: +353 (0)1 4027976, Fax: +353
(0)1 4027904

${ }^{2}$ NanoLab, Focas Institute, Dublin Institute of Technology, Kevin Street, Dublin 8, Ireland

${ }^{3}$ Institute of Inhalation Biology, Helmholtz Zentrum München, German Research Centre for Environmental Health, 85764 Neuherberg, Germany

${ }^{4}$ Department of Molecular Biology, University of Salzburg, Hellbrunnerstrasse 34, A-5020 Salzburg, Austria

*Corresponding author: eva.herzog@dit.ie 


\begin{abstract}
Single walled carbon nanotubes have gained enormous popularity due to a variety of potential applications which will ultimately lead to increased human and environmental exposure to these nanoparticles. This study was carried out in order to evaluate the inflammatory response of immortalised and primary human lung epithelial cells (A549 and NHBE) to single walled carbon nanotube samples (SWCNT). Special focus was placed on the mediating role of lung surfactant on particle toxicity. The toxicity of SWCNT dispersed in cell culture medium was compared to that of nanotubes dispersed in dipalmitoylphosphatidylcholine (DPPC, the main component of lung lining fluid). Exposure was carried out for 6 to 48 hours with the latter time-point showing the most significant responses. Moreover, exposure was performed in the presence of the pro-inflammatory stimulus tumour necrosis factor- $\alpha$ (TNF- $\alpha)$ in order to mimic exposure of stimulated cells, as would occur during infection. Endpoints evaluated included cell viability, proliferation and the analysis of inflammatory mediators such as interleukin (IL)-8, IL-6, TNF- $\alpha$ and macrophage chemoattractant protein-1 (MCP-1). Crocidolite asbestos was included as a well characterised, toxic fibre control. The results of this study showed that HiPco SWCNT samples suppress inflammatory responses of A549 and NHBE cells. This was also true for TNF- $\alpha$ stimulated cells. The use of DPPC improved the degree of SWCNT dispersion in A549 medium and in turn, lead to increased particle toxicity, however, it was not shown to modify NHBE cell responses.
\end{abstract}

\title{
Keywords:
}

Nanoparticles, single-walled carbon nanotubes (SWCNT), dipalmitoylphosphatidyl-choline (DPPC), lung surfactant, inflammatory mediators, A549 cell-line, NHBE cell-line, lung epithelium 


\section{Introduction}

Carbon nanotubes (CNT) [Iijima, 1991] have gained enormous popularity due to their unique properties, offering a wide range of potential applications within commercial, medical and environmental sectors and have been included in the list of representative manufactured nanomaterials for testing by the OECD [Dreher, 2004; OECD 2008]. It is anticipated that this will ultimately lead to significantly increased occupational and public exposure to CNT [Bottini et al., 2006]. For appropriate safety measures to be put in place, knowledge on the potential human and environmental impacts of such new materials is necessary.

The lungs are regarded as one of the main portals of entry for nanoparticles, which emphasises the importance of pulmonary toxicity evaluation. Since epithelial cells are able to produce a number of pro-inflammatory mediators, these cells are regarded as regulators of airway inflammation in addition to alveolar macrophages and fibroblasts [Takizawa, 1998] and the lung epithelium plays a key role in the modulation of inflammatory processes by releasing inflammatory cytokines such as monocyte chemoattractant protein-1 (MCP-1), IL-8 and TNF- $\alpha$ [Barlow et al., 2005; O'Brien et al., 1998].

In a recent study by Poland et al. (2008) it was shown that long multi-walled carbon

nanotubes (MWCNT) can result in asbestos-like pathogenic behaviour including inflammation and granuloma formation following direct exposure of the mesothelial lining of the body cavity of mice. Similar to asbestos, SWCNT can have a large aspect ratio, consisting of long, thin fibres with aerodynamic characteristics that allow them to be inhaled deeply into the lungs. Due to their length, they are difficult to remove by macrophages making them highly biopersistent, which is one of the main parameters of particulate toxicity [Donaldson et al., 2006]. The parallels drawn in terms of aspect ratio and fibrous nature highlight the need for further investigations of the comparative toxicity of CNT and asbestos fibres. Cytotoxicity, pro-inflammatory and fibrogenic factors released by lung target cells are believed to play a key role in the pathogenesis of asbestos toxicity [Becker et al., 2005b; Mossman and Churg 1998; Shukla et al., 2003b]. Thus a systematic comparison of SWCNT bundles and asbestos fibres is advantageous and was therefore conducted in this study. Although individual SWCNT are only a few nanometers in diameter, they are grown in bundles and remain as such in aqueous media and when suspended in cell culture medium [Casey et al., 2007a]. Due to their highly adsorptive nature, it is most likely that during 
human exposure, particles such as CNT would come into contact with a variety of different molecules leading to coating by various components present within a biological system [Casey et al., 2008; Hamilton et al., 2007]. Therefore, it was decided to use FCS as a media supplement in this study as it seemed to be the most relevant exposure scenario. However, it has been previously demonstrated that in presence of FCS the toxic potential of particles may be different compared to a FCS free environment as was seen with studies on the cytotoxicity of HiPco SWCNT and quartz particles where FCS supplemented culture medium significantly decreased the cytotoxicity of silica particles compared to particles suspended in FCS free medium [Davoren et al. 2007].

Upon inhalation, it is hypothesised that particles may deposit in the lung and come in contact with lung surfactant which consists of lipids and specific proteins that line the airliquid interface of the alveolar surface as well as the bronchi and trachea [Hook, 1993; Schürch et al., 1992]. Lung surfactant is synthesized and secreted by alveolar type II cells where it is stored in lamellar bodies [Dobbs et al., 1987; King et al. 1982], and it is physiologically important for lowering the surface tension of the pulmonary alveolar hypophase surface [Scarpelli 1968]. Furthermore it protects against pathogens by opsonising bacterial, fungal and viral surface oligosaccharides through surfactant protein binding [Griese 1999]. Experiments by Schürch et al. (1990) demonstrated that surfactant may aid in the displacement of particles from air to the aqueous phase and towards the lung epithelium. In addition, studies showed that when particles were present in peripheral airways and alveoli they exist in a completely immersed, wetted state below the surfactant film [Schürch et al, 1990]. Approximately $90 \%$ of bronchoalveolar lavage fluid (BALF) consists of phospholipids with dipalmitoylphosphatidylcholine (DPPC) being the most abundant and the substance mainly responsible for the surface tension lowering properties [Post and van Golde 1988]. Therefore, DPPC dispersed into physiological saline has been used as a simple model of lung surfactant and it was concluded that employing DPPC as dispersant for in vitro particle toxicity studies helps to mimic the real world exposure situation more closely and increases biological relevance [Wallace et al., 1987; 2006].

The aims of this in-vitro study were to determine whether SWCNT exposure can trigger an inflammatory response in lung epithelium and whether lung surfactants can alter the extent of dispersion and thereby the toxicity of SWCNT samples in comparison to 
medium suspended particles. The effects of the SWCNT were compared to those obtained with asbestos to enable comparison between the toxicity of these two particle types. In order to mimic inhalation exposure of SWCNT dust, particle samples were minimally processed and dispersed. Lung epithelial surface area is mainly made of type I cells. However there is no reliable human in vitro model available for this cell type and therefore alveolar epithelial type II cells are commonly used as a substitute [Donaldson et al., 2008]. This is reasonable since type II cells are able to proliferate and trans-differentiate into type I cells when the existing type I cell population is damaged in the lung alveoli [Bhaskaran et al., 2007]. The epithelial type II carcinoma cell line A549 were chosen as appropriate target cells for this study. To assess whether A549 cells are representative of primary cells regarding the aspects studied here, normal bronchial epithelial cells (NHBE) were also tested in parallel. 


\section{Material and Methods}

\section{Cell Culture}

\section{A549 human lung epithelial cells}

A549 cells from a human lung adenocarcinoma with the alveolar type II phenotype were obtained from ATTC (Manassas, VA, USA). Cells were cultured in RPMI 1640 (Gibco, Karlsruhe) supplemented with L-glutamine, penicillin and streptomycin (Gibco) and 10\% foetal calf serum (FCS, Biochrom, Berlin) in a humidified atmosphere containing $5 \% \mathrm{CO}_{2}$ at $37^{\circ} \mathrm{C}$. The A549 reporter gene cell lines, containing the promoter region of IL-8 or IL-6, were cultured as previously described by Oostingh et al. (2008). All cell culture reagents were obtained from PAA Laboratories (Pasching, Austria). The culture medium used for A549 cells will from herein be referred to as "A549 medium".

\section{Normal human primary bronchial epithelial cells}

Normal human primary bronchial epithelial cells (NHBE) were obtained from Clonetics $^{\mathrm{TM}}$ (Lonza, Switzerland) and were maintained in bronchial epithelial cell basal medium $\left(\mathrm{BEBM}^{\circledR}\right)$ plus SingleQuots ${ }^{\circledR}$ supplements as recommended by the manufacturer. Cells were used between passages 3-7. In the course of this study, this medium will from herein be referred to as "NHBE medium".

\section{Test Particles}

\section{HiPco SWCNT}

HiPco derived single-walled carbon nanotubes (SWCNT) were purchased from Carbon Nanotechnologies, Inc. (Houston, TX) and contained $10 \mathrm{wt} \%$ iron catalyst residues. The diameter distribution of these nanotubes was previously determined by Raman spectroscopy and ranged between $0.8-1.2 \mathrm{~nm}$ [Hedderman, 2006]. Atomic force microscopy (AFM) revealed HiPco SWCNT in their "as produced" state to exist in bundles on average $800 \mathrm{~nm}$ long with estimated bundle sizes of $2.6 \times 10^{14} \mathrm{~m}^{2}$. A BET surface area of $487.15 \mathrm{~m}^{2} / \mathrm{g}$ was measured based on nitrogen adsorption.

\section{Crocidolite asbestos}


Standard reference crocidolite asbestos (UICC) was obtained from SPI Supplies (Structure Probe Inc., West Chester, USA) and is characterized as described by Bowes and Farrow (1997). UICC crocidolite asbestos was reported to have a mean length of $\leq 5 \mu \mathrm{m}$ and a mean width of $<0.5 \mu \mathrm{m}$ [Lang et al., 2001]. BET surface area was reported to be $5.6 \mathrm{~m}^{2} / \mathrm{g}$ [Ono-Ogasawara and Kohyama 1999].

\section{Dispersion of SWCNT in cell culture medium}

A stock concentration of $500 \mu \mathrm{g} / \mathrm{ml}$ of SWCNT was prepared in the appropriate culture medium by vortexing the suspension three times for 5 seconds followed by sonication for $1 \mathrm{~min}$ in an ultrasonic bath (Sonorex RK52, Bandelin, Berlin, Germany). This procedure was repeated three times. Working concentrations of $0.195 \mu \mathrm{g} / \mathrm{ml}$ to $50 \mu \mathrm{g} / \mathrm{ml}$ were prepared by serial dilutions on a 96-well plate. Expressed in terms of mass per surface area, concentrations ranged from $0.06 \mu \mathrm{g} / \mathrm{cm}^{2}$ to $15.625 \mu \mathrm{g} / \mathrm{cm}^{2}$. Transmission electron microscopy (TEM) studies performed in our laboratory have indicated that SWCNT remain bundled at these concentrations after ultrasonic dispersion in culture medium [Casey et al., 2007a].

\section{Dispersion of SWCNT in DPPC}

A DPPC (Sigma) solution of $2.5 \mathrm{mg} / \mathrm{ml}$ was prepared in PBS by sonication for 10 minutes at $37^{\circ} \mathrm{C}$ using an ultrasonic bath. A $500 \mu \mathrm{g} / \mathrm{ml}$ stock concentration of SWCNT was prepared in DPPC/PBS solution followed by vortexing three times for 5 seconds each and subsequently sonicating for $1 \mathrm{~min}$ (Sonorex RK52, Bandelin, Berlin, Germany). This procedure was repeated three times. From these stock concentrations, working concentrations of $0.195 \mu \mathrm{g} / \mathrm{ml}$ to $50 \mu \mathrm{g} / \mathrm{ml}\left(0.06 \mu \mathrm{g} / \mathrm{cm}^{2}\right.$ to $\left.15.625 \mu \mathrm{g} / \mathrm{cm}^{2}\right)$ were prepared in A549 or NHBE medium containing 10\% DPPC/PBS so that the DPPC concentration was kept constant at $0.25 \mathrm{mg} / \mathrm{ml}$ over the concentration range studied.

\section{Dispersion of crocidolite asbestos}

Stock concentrations of $500 \mu \mathrm{g} / \mathrm{ml} \quad$ crocidolite asbestos $\left[\left(\mathrm{Na}_{2}\left(\mathrm{Fe}^{3+}\right)_{2}\left(\mathrm{Fe}^{2+}\right)_{3} \mathrm{Si}_{8} \mathrm{O}_{22}(\mathrm{OH})_{2}\right]\right.$ were prepared by diluting in the appropriate cell culture medium or DPPC/PBS. As asbestos was easily dispersible in aqueous solutions, no 
ultrasonication was required but short-term vortexing was used in order to disperse the samples. Working concentrations were prepared as described for SWCNT.

\section{Characterisation of SWCNT suspensions}

\section{Dynamic light scattering (DLS)}

Dynamic light scattering of particle solutions were obtained using the Nano-ZS system (Malvern Instruments).

\section{Light microscopy of particle exposed cells}

Cell monolayers were exposed to SWCNT samples or crocidolite asbestos as described for cell viability assays. Micrographs were obtained using a light microscope (Olympus IX70).

\section{$U V$-vis-NIR spectroscopy}

The method was adopted from Priya and Byrne (2008). Stock solutions of 4000 $\mu \mathrm{g} / \mathrm{ml} \mathrm{SWCNT}$ in DPPC/PBS were prepared as described earlier. This sample was then serially diluted using DPPC/PBS solution by a factor of 2 , down to $1.95 \mu \mathrm{g} / \mathrm{ml}$. Thus, the surfactant concentration was kept constant while that of the SWCNT was serially diluted. For SWCNT samples suspended in culture medium, a stock concentration of $500 \mu \mathrm{g} / \mathrm{ml} \mathrm{SWCNT}$ was prepared in DPPC/PBS, A549 or NHBE culture medium. These stock concentrations were diluted 1:10 in A549 or NHBE medium to obtain concentrations of $50 \mu \mathrm{g} / \mathrm{ml}$, followed by serial dilutions by a factor of 2 down to $0.195 \mu \mathrm{g} / \mathrm{ml}$ using the corresponding medium. Thus, the same test solutions were prepared as used for cell exposure studies. In addition, higher particle concentrations of up to $400 \mu \mathrm{g} / \mathrm{ml}$ were included. The absorbance at a wavelength of $633 \mathrm{~nm}$ was measured using a UV-vis-NIR spectrometer (Perkin-Elmer Lambda 900). This wavelength was chosen to be within the region of SWCNT absorbance

while avoiding interference from components of the cell culture medium [Casey et al., 2007a; Priya and Byrne, 2008]. 


\section{Cell exposures}

For cell viability, luciferase and protein release assays, cells were seeded in tissue culture treated 96-well plates at a density of $1 \times 10^{4}, 5 \times 10^{3}$, or $2.5 \times 10^{3}$ cells/well and exposed for 6, 24 and 48 hours, respectively. Following seeding, cells were incubated for 24 hours to adhere and obtain their normal morphology. Cells were then exposed to SWCNT samples, crocidolite asbestos dispersed in culture medium or DPPC/PBS at final concentrations of $0.195 ; 0.38 ; 0.78 ; 1.56 ; 3.125 ; 6.25 ; 12.5 ; 25$ and $50 \mu \mathrm{g} / \mathrm{ml}$. Culture medium only or culture medium containing $0.25 \mathrm{mg} / \mathrm{ml}$ DPPC/PBS served as negative control media, respectively.

In addition, all exposures were carried out on cells stimulated with recombinant tumour necrosis factor- $\alpha$ (rh-TNF- $\alpha$; Immunotools) or lipopolysaccharide derived from Pseudomonas aeruginosa (LPS-PA). A rh-TNF- $\alpha$ concentration of $10 \mathrm{ng} / \mathrm{ml}$ resulted in optimal cytokine induction of cells and was used as positive control stimulus.

Decreases in cell viability, promoter activation or protein release seen following 48 hours were always higher compared to 6 or 24 hours. Therefore, only results following 48 hours exposures are presented.

\section{Cell viability assay}

Cell viability was determined using the resazurin based CellTiterBlue ${ }^{\circledR}$ assay (Promega, Madison, USA) according to manufacturer's instructions.

As SWCNT have previously been shown to interact with a variety of organic molecules including colorimetric indicator dyes such as CellTiterBlue [Casey et al., 2007b], SWCNT were tested for interactions with the unconverted as well as the converted form of the CellTiterBlue dye resulting in a maximum decrease in fluorescence by $10 \%$, indicating only small interactions.

\section{Luciferase reporter gene assay}

Luciferase reporter gene assays were carried out under the same conditions as the cell viability assays. Following cell exposures, the luciferase assay was performed as described by Oostingh et al. (2008). Again, exposure over $48 \mathrm{~h}$ showed the most significant responses 
so that only $48 \mathrm{~h}$ data are presented here.

No significant interaction of SWCNT and the luminescence signal measured as endpoint for reporter-gene assays was found (data not shown).

\section{Real-time RT-PCR}

Cells were seeded at a density of $5 \times 10^{5}$ cells/ well in 12 well plates and were allowed to adhere for 24 hours. Cells were then exposed to a $500 \mu 1$ suspension of SWCNT in A549 medium with a final concentration of $0,1,10$ and $50 \mu \mathrm{g} / \mathrm{ml}$ for 6 or 24 hours. Following exposure, A549 cells were lysed using 1\% $\beta$-mercapto-ethanol in RLT buffer and cell solutions were transferred into QIAShredder spintubes (Qiagen). For RNA isolation and DNA removal the RNeasy Mini Kit (Qiagen) was used according to manufacturer's instructions. cDNA was generated using the first-strand cDNA synthesis kit (Amersham, Biosciences) and $\operatorname{pd}(\mathrm{N})_{6}$ as primer. Using the Taqman-system in the SybrGreen format, according to the manufacturer's instruction, quantitative PCR was performed using the following primers:

$\alpha$-Enolase 5' primer: 5'-GTT AGC AAG AAA CTG AAC GTC ACA-3', 3' primer: 5'-TGA AGG ACT TGT ACA GGT CAG-3'; IL-8 5'primer: 5'- ATG ACT TCC AAG CTG GCC GTG GCT-3', 3' primer: 5'-TCT CAG CCC TCT TCA AAA ACT TCT C-3'. Amplification of the housekeeping gene $\alpha$-Enolase served as internal control.

\section{Enzyme linked immunosorbent assays (ELISA)}

Enzyme linked immunosorbent assays (ELISA) were performed to determine if alterations in promoter activation also correspond to changes in protein secretion. In addition, this method was used to compare the effects on A549 compared to NHBE cells. ELISAs were performed for the cytokines IL-8, IL-6, TNF- $\alpha$ (Immunotools) and macrophage chemoattractant protein 1 (MCP-1, BenderMed Systems) following particle exposures for 24 or 48 hours (see table 1). Cells were exposed as described for the luciferase assay. As with the luciferase assays, 48 hour exposures resulted in the most profound effects so that these results were chosen for presentation and discussion.

The ELISAs were performed according to the manufacturer's instructions. The signal was developed by using 3,3',5,5'-Tetramethylbenzidin (TMB, Sigma, Wien, Austria) and the 
reaction was stopped using $2 \mathrm{M} \mathrm{H}_{2} \mathrm{SO}_{4}$. Absorbance was then read at $450 \mathrm{~nm}$ using a Tecan plate reader (Tecan, Grödig, Austria). All tests were performed at least in triplicate.

Carbon nanomaterials have been reported to be able to adsorb proteins including cytokines which could lead to false negative results during ELISA [Casey et al., 2007a,b; Monteiro-Rieviere and Inman, 2005; Zhang et al., 2007]. Following incubation of SWCNT and protein standards used for ELISA, no significant interactions could be observed for IL-8, IL-6 or MCP-1 independent of DPPC dispersion at the particle concentrations employed in this study. However, incubation of culture medium dispersed SWCNT with TNF- $\alpha$ protein standard did result in a $20 \%$ decrease in protein concentration (data not shown).

\section{Statistical analysis}

At least three independent experiments were conducted for each type of nanoparticle and toxicity endpoint. Test results for each assay were expressed as factor change compared to unexposed control \pm standard deviation $(\mathrm{SD})$. Control values were set as 1 . Differences between samples and control were evaluated using the statistical analysis package SPSS 14.0. Statistically significant differences were set at $p \leq 0.05$. Normality of data was confirmed with Q-Q percentile plots and Kolmogorov-Smirnov tests. Equality of variances was evaluated using Levène tests. One-way analysis of variances (ANOVA) followed by Dunnett's multiple comparison tests were performed for normally distributed samples with homogeneous variances. Non-parametric tests, namely Kruskal-Wallis followed by MannWhitney-u-tests were applied to samples without normal distribution and/or inhomogeneous variances. 


\section{Results and Discussion}

This study aimed to evaluate the effects of SWCNT and crocidolite asbestos exposure on the inflammatory mediator response of lung epithelial cells. Endpoints included cell viability, proliferation, cytokine promoter regulation of IL-8 and IL-6 and protein secretion of IL-8, IL-6, TNF- $\alpha$ and MCP-1. Special focus was placed on the modulating properties of DPPC dispersion on particle toxicity. Furthermore, effects of particle exposure on rh-TNF- $\alpha$ stimulated cells were investigated. The alveolar epithelial carcinoma cell line A549 and normal bronchial epithelial cells (NHBE) were chosen as target cells.

\section{Dispersion of HiPco SWCNT and asbestos fibres}

In this study, test particles were suspended in cell culture medium or DPPC/PBS solution. Concentrations of DPPC were chosen in order to assure complete particle coverage and mimic the degree of conditioning that would occur upon lung deposition. Due to the large surface area of SWCNT, $2.5 \mathrm{mg} / \mathrm{ml}$ of DPPC in PBS was calculated to be appropriate [based on W. Wallace, personal communication]. Asbestos, despite having smaller surface areas, was suspended in the same concentration of DPPC in order to allow direct toxicity comparisons. Due to the complexity of biological media, full characterisation of SWCNT is challenging and often not feasible. In the present study, Raman spectroscopy, DLS, UV-visNIR spectroscopy and light microscopy were carried out in order to assess the physical characteristics of SWCNT upon dispersion in DPPC and cell culture medium.

SWCNT grow in bundles and are hard to separate so that they typically form micronsized agglomerates which have a greater aerodynamic diameter and expose a smaller surface area compared to individually dispersed tubes [Donaldson et al., 2001]. As can be seen in Fig. 1, light microscopy observations showed that SWCNT were never completely dispersed in any of the media used in this study. Both dispersion of SWCNT in cell culture medium and DPPC did result in a certain degree of agglomeration, leading to cells being exposed to bundles of SWCNT rather than individual fibre shaped tubes. DLS measurements confirmed that all SWCNT samples were highly poly-dispersed and tended to precipitate. However, this was also the reason why this method was not applicable for further analysis of the SWCNT samples used. Alternatively, UV-vis absorption analysis was carried out to analyse SWCNT 
suspensions as described by Priya and Byrne (2008). A linear and constant increase in absorbance could be observed with increasing SWCNT concentrations for all dispersant vehicles used (Fig. 2). This indicates that within the concentration range of SWCNT employed in this study, SWCNT were present as bundles and there is no evidence of a transition to dispersed isolated tubes at low concentrations, as is observed in water/sodium dodecyl benzene sulfonate suspensions at $0.07 \mathrm{mg} / \mathrm{ml}$. This effect was independent of the type of suspension vehicle used. Light microscopy confirmed the presence of SWCNT agglomerates of various sizes with diameters of micrometer range distributed on top of exposed cells (Fig. 1). Light microscopy also showed that the relative agglomeration of SWCNT clearly differed between SWCNT dispersed in A549 medium (Fig. 1 a) and DPPC followed by addition to A549 medium (Fig. 1 b). Dispersion in A549 medium resulted in the least uniform dispersion leading to the formation of large, condensed agglomerates of SWCNT. In contrast, either DPPC or NHBE medium dispersion led to a more uniform SWCNT dispersion, resulting in greater exposure of cells to SWCNT. Using UV-vis absorption spectroscopy, the same absorbance values were observed for SWCNT suspensions following DPPC or NHBE medium dispersion (Fig. 2). However, dispersion with A549 culture medium in the absence of DPPC resulted in significantly lower absorbance, indicating higher amounts of SWCNT being suspended by DPPC or NHBE medium compared to A549 medium. Improved dispersion of SWCNT would ultimately modify their toxicological behaviour as well as their aerodynamic and therefore deposition characteristics [Donaldson et al., 2001]. In contrast to SWCNT, the dispersion of asbestos was independent of the type of dispersion medium (Fig. 1 c, d) and it was easily dispersible leading to single fibres.

The fact that DPPC may aid in the dispersion of SWCNT agrees with a study by Sager et al. (2007) who reported that DPPC in combination with bovine serum albumin (BSA) produces a satisfactory dispersion of carbon nanoparticles. In a recent study by Porter et al. (2008), authors also employed DPPC as a non-toxic the dispersant for MWCNT. Dispersion using DPPC may also lead to adsorption of surfactant components onto the particles. This could lead to conditioning of particle surfaces which may affect their expression of cytotoxicity or genotoxicity [Wallace et al., 2006]. This was seen for diesel exhaust particles (DEP) and also silica particles conditioned by DPPC [Keane et al., 1991; 
Murray et al., 2005; Wallace et al., 2006]. A recent study by Foucaud et al. (2007) demonstrated that the oxidative potential of Printex 90 carbon black nanoparticles can be modified by dispersion in medium containing DPPC and BSA. DPPC dispersion resulted in greater oxidative potential of particles as compared to particles suspended in physiological saline. On the other hand, coating with lung surfactant might mask their oxidative potential leading to decreased reactivity and attenuated toxicity [Gao et al., 2001]. Therefore, the next step of this study was to investigate the effects of SWCNT exposure on the inflammatory response of lung epithelial cells upon SWCNT exposure and examine if DPPC dispersion may modulate cell responses.

\section{Effects of HiPco SWCNT and asbestos exposure on viability of lung epithelial cells}

To assess whether any effects on inflammatory mediator releases could be due to decreased cell viability, the resazurin-based CellTiterBlue assay was carried out in parallel with all assays. Exposure of A549 cells to culture medium dispersed SWCNT at the concentration range tested did not result in any reduction of cell viability, independent of cell stimulation with rh-TNF- $\alpha$ (Fig. 3 a, b). In contrast, a dose-dependent increase in CellTiterBlue fluorescence was observed. This agrees with previous studies showing no cytotoxicity of A549 cells at concentrations up to and including $50 \mu \mathrm{g} / \mathrm{ml}$ [Davoren et al., 2007; Herzog et al., 2007]. Therefore, any effects on inflammatory mediator response would not be due to loss of cell viability. However, significant cytotoxic effects could be seen for A549 cells exposed to DPPC dispersed SWCNT (Fig. 3 a, b). NHBE cells did not show a loss in viability under any exposure condition (Fig. 4 a).

Exposure of A549 or NHBE cells to asbestos resulted in some loss of cell viability of up to $20 \%$. No differences between culture medium and DPPC dispersion could be observed for non-stimulated cells (Fig. 3 c, d; Fig. 4 b).

\section{Effects of HiPco SWCNT exposure on selected inflammatory mediators}

One of the main objectives of this study was to address the question whether SWCNT exposure has the potential of modulating the immunological response of lung epithelial cells. Inflammatory responses are mediated by a variety of signalling molecules, and airway epithelial cells are known to be a major source of pro-inflammatory cytokines [Driscoll 
1997]. Stimulation of A549 cells to release inflammatory mediators upon particle exposure has been frequently used to discriminate between pathogenic and non-pathogenic particles [Ovrevik et al. 2005]. As a major attractor and activator of polymorphonuclear neutrophils (PMN) to the site of inflammation, IL-8 belongs to the group of pro-inflammatory cytokines. It is partly involved in the initiation and maintenance of airway inflammation and has been implicated in a variety of chronic inflammatory diseases [Luster and Simeonova, 1998]. In order to analyse immunological responses caused by particle exposure, stable transfected A549 cells containing the promoter regions for the cytokines IL- 8 or IL- 6 were used as a screening tool.

Using A549-IL8 reporter gene cells, it was observed that exposure of cells to HiPco SWCNT resulted in a dose- and time-dependent reduction in IL-8 promoter activation as measured by decreased luciferase activity reaching levels of only $64 \%$ compared to control cells with significant decreases starting at $12.5 \mu \mathrm{g} / \mathrm{ml}$ (Fig. 5 a). Recombinant human TNF- $\alpha$ was used as positive control stimulus and resulted in increases in IL-8 promoter activation by a factor of 3 following 6 hours exposure which increased up to 8 fold following 48 hours. This demonstrates that rh-TNF $\alpha$ is suitable as positive control stimulus. Furthermore, it shows the validity and adequateness of the test systems and endpoints used. Stimulation with LPS-PA could only stimulate cells by a factor of $1.3,1.7$ and 2.2 following 6,24 and 48 hours exposures.

Real time RT-PCR was used in order to confirm the effects observed and it was shown that not only was the IL-8 promoter activation inhibited by SWCNT exposure but also IL-8 mRNA in A549 cells significantly decreased following 6 and 24 hours exposures. A decrease by $30 \%$ could be observed following 6h exposure of A549 cells to $50 \mu \mathrm{g} / \mathrm{ml}$ of HiPco SWCNT. Following 24 hours, IL-8 mRNA was decreased by $40 \%$ compared to unexposed control cells. In contrast, rhTNF-a exposure led to increases of up to 45 and 16 fold for 6 and 24 hours, respectively. This confirms that the luciferase reporter-gene cellsystem used in this study is an adequate test method and as it represents a more suitable system for screening purposes, it was preferred to mRNA analysis for further investigations within the context of this study.

In parallel to promoter activation of the IL- 8 gene, IL-8 protein release was measured using ELISA and decreases of up to $40 \%$ were observed (Fig. 6 a). On the one hand, this 
confirms the effects seen using reporter gene assays and furthermore, it shows that the particles were also effective on the level of protein production of the cells.

Similar to the effects observed with IL-8, HiPco SWCNT decreased the promoter activation and protein release of IL-6 in A549 cells. Following 48 hours, decreases in IL-6 protein release of $27 \%$ could be observed following exposure to culture medium dispersed nanotubes in the absence of rh-TNF- $\alpha$ stimulation (Fig. 6 c).

Levels of TNF- $\alpha$ protein release in A549 cells remained below detection limits of the test system and could therefore not be determined with the ELISA system used. Instead, macrophage chemoattractant protein-1 (MCP-1) was included as a further endpoint and results for A549 cells are shown in Fig. 6 (e, f). MCP-1 appeared to be more sensitive when compared to IL-8 and IL-6. Following 48 hours exposure, MCP-1 levels were reduced by more than $40 \%$ (Fig. 6 e).

In parallel to exposures carried out on A549 cells, the normal bronchial epithelial cell line NHBE was used in order to assess the effects of particle exposure on primary cells as this may be considered a more relevant model to mimic human exposure. When NHBE cells were exposed to SWCNT, IL-8 and IL-6 were reduced by $22 \%$ and $36 \%$, respectively, following 48 hours exposure (Fig. 7 a, c). Levels of TNF- $\alpha$ and MCP-1 protein remained below detection limits and could therefore not be analysed. Overall, the responses of A549 and NHBE cells to culture medium dispersed SWCNT did not differ significantly.

No reductions in cell viability were found following exposure to cell culture medium dispersed SWCNT. Furthermore, there were no significant interactions between SWCNT and the test systems employed within the concentration range tested. This demonstrates that under the conditions employed, culture medium dispersed HiPco SWCNT exposure results in the suppression of inflammatory mediator response of A549 and NHBE cells which would indicate that epithelial cells do not elicit an inflammatory alarm response upon SWCNT exposure. Suppression of inflammatory mediator responses by SWCNT would agree with studies by Shvedova et al. (2008) who have seen increased bacterial infectivity in vivo and decreased bacterial uptake and killing in vitro in mice exposed to SWCNT followed by induction of a pulmonary infection. It also indicates that the particles are not significantly contaminated with lipopolysaccharide (LPS) which would otherwise lead to inflammatory activation. 
In previous studies it was shown that SWCNT interact with components of cell culture media including FCS, riboflavin and phenol red [Casey et al., 2007a]. It was also demonstrated that these interactions can lead to indirect toxicity of SWCNT due to nutrient adsorption as seen by decreased cell viability and reductions in cell proliferation [Casey et al., 2008]. Therefore, indirect effects of SWCNT exposure on cell viability and IL-8 promoter activation were assessed using the A549-IL8 reporter gene assay and no significant indirect effects were observed for the concentration range of SWCNT tested (data not shown).

\section{Effects of crocidolite asbestos exposure on selected inflammatory mediators}

The second question to be addressed within this study was whether the response seen following SWCNT exposure resembles that of asbestos exposure. Crocidolite asbestos belongs to the group of amphibole asbestos, has a high iron content and is often considered the most pathogenic and oncogenic type of asbestos [Albin et al., 1994; Heintz et al., 1993; Mossman et al., in press;]. It consists of long, rigid, rod-like fibres that are more difficult to be broken down in tissue compared to chrysotile forms [Shukla et al., 2003b]. Fibre morphology but also chemical composition are believed to be crucial determinants of bioreactivity of asbestos [Mossman et al., 2007; Shukla et al., 2003a], so that the same might be true for nanoparticles such as SWCNT. The inflammatory cytokines IL-8 and IL-6 have been shown to play a direct role in asbestos toxicity and are reported to be produced by lung epithelial cells in direct response to asbestos fibres [Luster and Simeonova 1998]. Therefore, cytokine production was regarded as a valuable endpoint for this study and to our knowledge, no studies comparing the toxicity of SWCNT and crocidolite asbestos on epithelial cells in vitro exist to date.

Reporter-gene cell assays and ELISA revealed comparable data. Illustrated are data from protein analysis as this endpoint seemed to result in lower data variability. When A549 cells were exposed to asbestos, decreases could only be measured for MCP-1 protein release which was inhibited by up to $40 \%$ (Fig. 8 e). The same decrease in MCP-1 could be seen following SWCNT treatment. In contrast to the effects of SWCNT, IL-8 and IL-6 protein levels slightly increased following culture medium dispersed asbestos exposure for 48 hours (Fig. 8 a, c). No effect could be seen following 24 hour exposure. In NHBE cells, small 
decreases of up to $11 \%$ were seen for IL-8 and no effect was seen for IL-6 (Fig. 9). Due to the reductions in cell viability observed following asbestos exposures it was concluded that crocidolite asbestos has no significant effects on IL-8 or IL-6 responses of NHBE cells in this study. However, it stimulates cytokine responses of A549 cells and significantly decreases their MCP-1 release (Fig. 7). Other studies evaluating the effects of crocidolite asbestos on A549 and NHBE cells reported much stronger increases of IL-6 and IL-8 than observed here which might be due to differences in exposure conditions or asbestos origin [Luster and Simeonova 1998; Simeonova et al., 1997].

\section{Effects of particle exposure on rh-TNF- $\alpha$ stimulated cells}

The next question of interest was whether the effects of particle exposure differ between cells in a healthy and a diseased state. It is reported that nanoparticle exposure of individuals with pre-existing diseases may exacerbate some respiratory effects due to inflammation and oxidative stress [Ferin et al., 1992; Utell and Frampton, 2000a, 2000b; Seaton et al., 1995]. Therefore, evaluating the effects of SWCNT exposure on rh-TNF- $\alpha$ - or LPS-induced cells may give an indication of whether the presence of an infection may give rise to increased SWCNT toxicity compared to normal, unstimulated cells or whether the presence of SWCNT can modulate inflammatory responses during infections. It has also been proposed that bacterial products such as LPS associated with particles may have stimulatory effects on the cytokine production of macrophages and maybe also epithelial cells [Becker et al., 2005a; Hofer et al., 2004]. While epithelial cells only slightly respond to LPS when compared to macrophages, they do express TLR receptors and have been shown to release IL-8 in response to treatment with different kinds of LPS with LPS from Pseudomonas aeruginosa (LPS-PA) being most effective [Hansen et al., 1999]. There are also reports of diesel particles having suppressive or synergistic effects on LPS-induced cytokine production [Amakawa et al., 2003; Hofer et al, 2004; Yang et al., 2001].

TNF- $\alpha$ is a known inflammatory mediator that leads to the induction of IL-8 and IL-6 and is expressed in response to infection in a variety of cell types including airway epithelium and macrophages. A rh-TNF- $\alpha$ concentration of $10 \mathrm{ng} / \mathrm{ml}$ was identified as most suitable as it results in a medium stimulation of cells allowing decreases as well as further 
increases of cytokine production. In addition, it could serve as positive control for the induction of IL-8 and IL-6.

Stimulation with rh-TNF- $\alpha$ resulted in an increase in IL-8 promoter activation by an average factor of $8.3(830 \%)$ compared to non-stimulated control cells (data not shown). Protein release of IL-8 and IL- 6 was increased by up to 10 fold following TNF- $\alpha$ stimulation. However, SWCNT exposure did not result in any further increase in the stimulation induced by rh-TNF- $\alpha$. Cell viability following SWCNT exposure was independent of TNF- $\alpha$ stimulation (Fig. 3 b). In contrast, compared to stimulated control cells, the presence of SWCNT decreased IL-8 promoter activation of A549 cells by more than $20 \%$, similar to the effects seen for un-stimulated cells (Fig. 5 b). The decrease in IL-8 and IL-6 protein release seen in non-stimulated cells upon SWCNT exposure was significantly inhibited by the presence of rh-TNF- $\alpha$ stimulation leading to reduction of only $16 \%$ for IL- 8 and no significant reductions in IL-6 (Fig. $6 \mathrm{~b}+\mathrm{d}$ ) compared to $40 \%$ and $27 \%$ for non-stimulated cells, respectively. Therefore, co-stimulation with rh-TNF- $\alpha$ seemed to decrease the suppressive effects of SWCNT on IL-6 and IL-8. MCP-1 protein response was independent of rh-TNFa stimulation (Fig. 6 f).

The decreases in mediator responses seen in TNF- $\alpha$ stimulated cells upon addition of SWCNT may also be explained by the adsorbing properties of these particles. As seen in previous studies, SWCNT with their large surface area can interact with a variety of organic molecules [Casey et al., 2007a,b; Casey et al., 2008; Guo et al., 2008] and have been shown to reduce TNF- $\alpha$ levels in culture medium by up to $20 \%$ in this study (see section on materials and methods). Therefore, decreased inflammatory mediator responses with increasing concentrations of SWCNT may also be due to decreased levels of TNF- $\alpha$ available for the cells due to binding if TNF- $\alpha$ onto SWCNT.

In general, the decreases in inflammatory mediator responses seen for SWCNT exposures even in the presence of inflammatory stimulation would again agree with rodent studies by Shvedova et al. (2008) reporting enhanced pulmonary infectivity following SWCNT exposure.

Following asbestos exposure, rh-TNF- $\alpha$ stimulated cells decreased their IL-8 and IL-6 protein release compared to un-stimulated cells (Fig. $8 b+$ d). Again, no modulating effect 
of rh-TNF- $\alpha$ stimulation could be seen for the effects of SWCNT or asbestos exposure on MCP-1 release or viability of A549 cells (Fig. 6 e, f; Fig. 8 e, f; Fig. 3 d).

NHBE responded differently to A549 cells and seemed to be significantly more responsive to rh-TNF- $\alpha$ treatment. While non-stimulated NHBE cells showed reductions of $22 \%$ and 36\% upon SWCNT treatment for IL-8 and IL-6 (Fig. 7 a, c), the cytokine levels of stimulated cells exposed to SWCNT decreased by $51 \%$ and $64 \%$, respectively (Fig. 7 b, d). This difference may be explained by the differences in cell type with NHBE cells being normal primary epithelial cells of bronchial origin and A549 cells being a carcinoma cell line originating from alveolar epithelium.

SWCNT exposure of A549 cells stimulated with LPS-PA showed significantly higher decreases in cytokine responses (Fig. 5 c) but also high levels of cytotoxicity (data not shown). A LPS-PA concentration as high as $25 \mu \mathrm{g} / \mathrm{ml}$ was needed in order to achieve significant cytokine induction in A549 cells, leading to increases of IL-8 promoter activation and protein release by an average of 2.2 fold following 48 hours exposure, so that it was assumed not to be a realistic exposure scenario and LPS stimulation was not included in any of the further studies.

Taken together, rh-TNF- $\alpha$ treated cells did show responses different to that of non-stimulated ones. However, neither SWCNT nor asbestos particles were able to further increase inflammatory mediator responses of stimulated cells.

The effects of DPPC dispersion on SWCNT and asbestos toxicity

The final objective of this study was to determine whether DPPC dispersion influences the toxicity of particle exposure. Exposure of cells to medium containing DPPC did not alter cell responses compared to cells exposed to culture medium only. However, as can be seen in Fig. 6 and 7, DPPC dispersion of SWCNT did result in increased suppression of IL-8, IL-6 and MCP-1 in A549 cells compared to culture medium dispersed nanotubes. This effect was even more pronounced when cells were stimulated with rh-TNF- $\alpha$ (Fig. 5 b and Fig. 6 b, d, f). Therefore, it seems that during an ongoing inflammation, these cells might be more vulnerable to the effects of SWCNT in DPPC.

As can be seen in Figure 8, DPPC dispersion could also modulate the effects of asbestos on un-stimulated A549 cells, leading to decreases in IL-8 and IL-6 of up to 50 and 
$20 \%$, respectively (Fig. 8 a, c) whereas increases by around $20 \%$ were seen in the absence of DPPC for both endpoints. Dispersion in DPPC also led to decreases in IL-6 protein of rhTNF- $\alpha$ stimulated cells by up to $23 \%$ which was not apparent in the absence of DPPC (Fig. 8 d). The MCP-1 release by A549 cells to asbestos seems to be independent of DPPC (Fig. 8 ef) and so were the effects of particle exposure on NHBE cells (Fig. 7 and Fig. 9). Cell viability of non-stimulated A549 cells post asbestos exposure was independent of DPPC dispersion (Fig. 3 c). Dispersion in DPPC only caused decreased viability of cells stimulated with TNF- $\alpha$ (Fig. 3 d). The same was true for the viability of NHBE cells (Fig. 4 b).

As seen in Figures 1 and 2, DPPC improved SWCNT dispersion, resulting in more cells being exposed to SWCNT which may in turn result in increased loss of cell viability and therefore inflammatory response. It was thus hypothesized that the type of dispersion vehicle used for studying SWCNT in vitro greatly influences their cellular effects. In previous studies it was demonstrated that improved dispersion of carbon black nanoparticles can lead to increased in vivo inflammation and damage compared to poorly dispersed nanoparticles [Shvedova et al., 2007]. Therefore, improved dispersion of SWCNT may explain the increases in particle toxicity seen in this study.

The degree of SWCNT dispersion was the same for NHBE medium with or without DPPC (Fig. 2). This can be explained by the fact that NHBE cell responses were not modified by the presence of DPPC. No significant influence of DPPC on asbestos dispersion or cytotoxicity was observed. Therefore, it remains unknown why DPPC dispersion can also modify the inflammatory response of A549 cells to asbestos fibres. As a surfactant, DPPC forms micellar structures through their interaction with the particles. Therefore, it could be hypothesised that while "unstructured" DPPC may not affect cell responses, changes in the arrangement of hydrophilic and hydrophobic regions of DPPC molecules due to the presence of particles may render it more toxic to A549 cells. DPPC dispersion may also lead to changes in particle surface chemistry [Buford et al., 2007; Wallace et al., 2006]. Particle coating by DPPC may modify or increase particle uptake by cells leading to particles coming into contact with different cellular compartments/targets which could change toxic responses. Different degrees of particle uptake may also explain the discrepancies observed between A549 and NHBE cells. In contrast to bronchial epithelial cells such as NHBE cells, A549 cells represent alveolar type II cells, that are able to produce lung surfactant. In addition, they 
possess surface receptors that recognize and internalize surfactant for recycling which may lead to increased interaction and uptake of DPPC coated particles by A549 cells compared to NHBE cells. This may also explain the changes in cell responses seen following asbestos exposure, which seems to be independent of the degree of particle dispersion. Therefore, future studies will investigate the effects of DPPC dispersion on particle uptake.

The use of DPPC may also modify the oxidative potential of SWCNT and asbestos as has also been shown for carbon black particles [Foucaud et al., 2007]. However, further physical and chemical characterization of the interactions between DPPC and particles/fibres are needed for better understanding of the mechanisms taking place. Investigations into the oxidative potential of SWCNT under the conditions employed in this study are currently underway. As DPPC dispersion significantly modulated cellular responses following SWCNT and asbestos exposure, the use of DPPC as dispersant vehicle may be of great importance and relevance for any in vitro studies investigating the effects of particle exposure on lung target cells.

\section{Conclusion}

To conclude, this study showed that exposure to HiPco SWCNT samples can lead to the suppression of a variety of inflammatory mediators including IL-8, IL-6 and MCP-1 in vitro. This was true for human type II alveolar epithelial cells (A549) as well as primary normal human bronchial cells (NHBE). Even though this means that SWCNT exposure does not seem to activate inflammation in A549 and NHBE cells, suppression of an immunological response may have negative consequences as the normal status quo of the immune system has changed and may render the immune system less reactive towards infections. Furthermore, activation of an immune response is needed in case of oxidative stress triggered by these particles and cell signalling by lung epithelial cells is of utmost importance in order to attract phagocytic cells such as monocytes and macrophages, which represent the first line of defence against invading particles and are needed for tissue clearance, to the site of particle deposition. 
Comparing the two cell types employed in this study, NHBE and A549 cells appeared to respond similarly to the presence of medium dispersed SWCNT. However, NHBE cells stimulated by rh-TNF- $\alpha$ seemed to be significantly more sensitive to SWCNT exposure. Stimulation with rh-TNF- $\alpha$ was used as a model for diseased epithelium and it was demonstrated that cell responses selectively differed from that of un-stimulated cells.

No definite conclusion can be drawn as to whether HiPco SWCNT samples have the potential of reacting in an asbestos-like manner. Only asbestos was able to slightly increase IL-8 and IL-6 responses. In contrast, both particle types were able to selectively decrease IL8, IL-6 and MCP-1 and changed their reactivity following DPPC dispersion. However, suppression of IL-8 was generally greater following HiPco SWCNT exposure compared to asbestos. Therefore, HiPco SWCNT exposures showed similarities but also differences to crocidolite asbestos so that risk assessment needs further comparative studies. Dispersion of particles in DPPC helped to mimic pulmonary exposure more closely. Effective dispersion of nanoparticles and the use of biologically relevant media are important for accuracy in toxicity assays. In this study it was shown that DPPC can improve SWCNT dispersion in A549 medium which in turn leads to significant increases in particle toxicity. 


\section{References}

Albin, A, Pooley, F.D., Strömberg, U., Attewell, R., Mitha, R., Welinder, H., 1994. Retention patterns of asbestos fibres in lung tissue among asbestos cement workers. Occup. Environ. Med. 51, 205- 211.

Amakawa, K., Terashima, T., Matsuzaki, T., Matsumaru, A., Sagai, M., Yamaguchi, K., 2003. Suppressive effects of diesel exhaust particles on cytokine release from human and murine alveolar macrophages. Exp. Lung. Res. 29, 149-164.

Barlow, P.G., Clouter-Baker, A., Donaldson, K., MacCallum, J., Stone, V., 2005. Carbon black nanoparticles induce type II epithelial cells to release chemotaxins for alveolar macrophages. Particle and Fibre Toxicology 2:11; doi: 10.1186/1743-8977-2-11 [Online 06 December 2005].

Bhaskaran , M., Kolliputi, N., Wang, Y., Gou, D.,Chintagari, N.R., Liu, L., 2007. Transdifferentiation of alveolar epithelial type II cells to type I cells involves autocrine signaling by tranforming growth factor b1 through the Smad pathway. J. Biol. Chem. 282, 3968-3976.

Becker, S., Dailey, L., Soukup, J.M., Silbajoris, R., Devlin, R.B., 2005a. TLR-1 is involved in airway epithelial cell response to air pollution particles. Toxicol. Appl. Pharmacol. 203, $42-52$. 
Becker, S., Mundandhara, S., Devlin, R.B., Madden, M., 2005b. Regulation of cytokine production in human alveolar macrophages and airway epithelial cells in response to ambient air pollution particles: further mechanistic studies. Toxicol. Appl. Pharmacol. 207, 269-275.

Bottini, M., Bruckner, S., Nika, K., Bottini, N., Bellucci, S., Magrini, A., Bergamaschi, A., Mustelin, T., 2006. Mulit-walled carbon nanotubes induce T lymphocyte apoptosis. Toxicol. Lett. 160, 121-126.

Bowes, D.R., Farrow, C.M., 1997. Major and trace element composition of the UICC standard asbestos samples. Am. J. Ind. Med. 32, 592-594.

Buford, M.C., Hamilton, R.F., Holian, A., 2007. A comparison of dispersing media for various engineered carbon nanoparticles. Particle and Fibre Toxicology 4:6, doi:10.1186/1743-8977-4-6 [Online 27 July 2007].

Casey, A., Davoren, M., Herzog, E., Lyng, F.M., Byrne, H.J., Chambers, G., 2007a. Probing the interaction of single walled carbon nanotubes within cell culture medium as a precursor to toxicity testing. Carbon 45, 34-40.

Casey, A., Herzog, E., Davoren, M., Lyng, F.M., Byrne, H.J., Chambers, G., 2007b. Spectroscopic analysis confirms the interactions between single walled carbon nanotubes and various dyes commonly used to assess cytotoxicity. Carbon 45, 1425-1432. 
Casey, A., Herzog, E., Lyng, F.M., Byrne, H.J., Chamber, G., Davoren, M., 2008. Single walled carbon nanotubes induce indirect cytotoxicity by medium depletion in A549 lung cells. Toxicol. Lett. 179, 78-84.

Davoren, M., Herzog, E., Casey, A., Cottineau, B., Chambers, G., Byrne, H.J., Lyng, F.M., 2007. In vitro toxicity evaluation of single walled carbon nanotubes on human A549 lung cells. Toxicol. In Vitro 21, 438-448.

Dobbs, L.G., Wright, J.R., Hawgood, S., Gonzalez, R., Venstrom, K., Nellenbogen, J., 1987. Pulmonary surfactant and its components inhibit secretion of phosphatidylcholine from cultured rat alveolar type II cells. Proc. Natl. Acad. Sci. U S A 84, 1010-1014.

Donaldson, K., Aitken, R., Tran, L., Stone, V., Duffin, R., Forrest, G., Alexander, A., 2006. Carbon nanotubes: A review of their properties in relation to pulmonary toxicology and workplace safety. Toxicol. Sci. 92, 5-22.

Donaldson, K., Borm, P.J.A., Oberdorster, G., Pinkerton, K.E., Stone, V., Tran, C.L., 2008. Concordance between in vitro and in vivo dosimetry in the proinflammatory effects of lowtoxicity, low-solubility particles: The key role of the proximal alveolar region. Inhal. Toxicol. 20, 53-62.

Donaldson, K., Stone, V., Clouter, A., Renwick, L., MacNee, W., 2001. Ultrafine particles. Occupat. Environ. Med. 58, 211-216. 
Dreher, K.L., 2004. Health and environmental impact of nanotechnology: Toxicological assessment of manufactured nanoparticles. Toxicol. Sciences. 77, 3-5.

Driscoll, K.E., Carter, J.M., Hassenbein, D.G., Howard, B., 1997. Cytokines and particleinduced inflammatory cell recruitment. Environ. Health Perspect. 105, 1159-1164.

Ferin, J., Oberdorster, G., Penney, D.P., 1992. Pulmonary retention of ultrafine particles in rats. Am. J. Respir. Cell Mol. Biol. 6, 535-542.

Foucaud, L., Wilson, M.R., Brown, D.M., Stone, V., 2007. Measurement of reactive species production by nanoparticles prepared in biologically relevant media. Toxicol. Lett. 174, 1-9.

Gao, N., Keane, M., Ong, T., Ye, J., Miller, W., Wallace, W., 2001. Effects of phospholipid surfactant on apoptosis induction by respirable quartz and kaolin in NR8383 rat pulmonary macrophages. Toxicol. Appl. Pharmacol. 175, 217-225.

Griese, M., 1999. Pulmonary surfactant in health and human lung disease: state of the art. Eur. Respir. J. 13, 1455-1476.

Guo, L., Von Dem Bussche, A., Buechner, M., Yan, A., Kane, A.B., Hurt, R.H., 2008. Adsorption of essential micronutrients by carbon nanotubes and the implications for nanotoxicity testing. Small 4, 721-727. 
Hamilton Jr, R.F., Raymond, F., Buford, M.C., Wood, M.B., Arnone, B., Morandi, M., Holian, A., 2007. Engineered carbon nanoparticles alter macrophage immune function and initiate airway hyper-responsiveness in the BALB/c mouse model. Nanotoxicology 1, 104117.

Hansen, L.A., Poulsen, O.M., Würtz, H., 1999. Endotoxin potency in the A549 lung epithelial cell bioassay and the limulus amebocyte lysate assay. J. Immunol. Methods 226, 49-58.

Hedderman, T.G., 2006. PhD Thesis, 91-103. Dublin.

Heintz, N.H., Janssen, Y.M., Mossman, B.T., 1993. Persistent induction of c-fos and c-jun expression by asbestos. Proc. Natl. Acad. Sci. USA 90, 3299-3303.

Herzog, E., Casey, A., Lyng, F.M., Chambers, G., Byrne, H.J., Davoren, M., 2007. A new approach to the toxicity testing of carbon based nanomaterials - the clonogenic assay. Toxicol. Lett. 174, 49-60.

Hofer, T.P.J., Bitterle, E., Beck-Speier, I., Maier, K.L., Frankenberger, M., Heyder, J., Ziegler-Heitbrock, L., 2004. Diesel exhaust particles increase LPS-stimulated COX-1 expression and PGE2 production in human monocytes. J. Leukocyte Biol. 75, 856-864.

Hook, G.E.R., 1993. Does pulmonary surfactant aid in defence of the Lungs? Environ. Health Perspect. 101, 98-99. 
Iijima, S., 1991. Helical microtubules of graphitic carbon. Nature 354, 56-59.

Keane, M.J., Xing, S.G., Harrison, J., Ong, T., Wallace, W.E., 1991. Genotoxicity of diesel exhaust particles dispersed in simulated pulmonary surfactant. Mutat. Res. 260, 233-238.

King, R.J., 1982. Pulmonary surfactant. J. Appl. Physiol. 53, 1-8.

Lang, D.S., Schocker, H., Hockertz, S., 2001. Effects of crocidolite asbestos on human bronchoepithelial-dependent fibroblast stimulation in coculture: the role of IL-6 and GMCSF. Toxicology 159, 81-98

Luster, M.I., Simeonaova, P.P., 1998. Asbestos induces inflammatory cytokines in the lung through redox sensitive transcription factors. Toxicol. Lett. 102, 271-275.

Monteiro-Riviere, N.A., Inman, A.O., 2006. Challenges for assessing carbon nanomaterial toxicity to the skin. Carbon 44, 1070-1078.

Mossman, B.T., Borm, P.J., Castranova, V., Costa, D.L., Donaldson, K., Kleeberger, S.R., 2007. Mechanisms of action of inhaled fibers, particles and nanoparticles in lung and cardiovascular diseases. Particle and Fiber Toxicology 4:4; doi: 10.1186/1743-8977-4-4 [Online 30 May 2007]. 
Mossman, B.T., In press. Assessment of the pathogenic potential of asbestiform vs. nanoasbestiform particulates (cleavage fragments) in in vitro (cell or organ culture) models and bioassays. Regul. Toxicol. Pharmacol. doi: 10.1016/j.yrtph.2007.10.004 [Online 11 October 2007].

Mossman, B.T., Churg, A., 1998. Mechanisms in the pathogenesis of asbestos and silicosis. Am. J. Respir. Crit. Care Med. 157, 1666-1680.

Murray, D., Harrison, J., Wallace, W., 2005. A 13C CP/MAS and 31P NMR study of the interactions of dipalmitoylphosphatidyl choline with respirable silica and kaolin. J. Colloid Interface Sci. 288, 166-170.

O’Brien, A.D., Standiford, T.J., Christensen, P.J., Wilcoxen, S.E., Paine, R.3rd., 1998. Chemotaxis of alveolar macrophages in response to signals derived from alveolar epithelial cells. J. Lab. Clin. Med. 13, 417-424.

Organisation for Economic Co-operation and Development, 2008. Environment directorate joint meeting of the chemicals committee and the working party on chemicals, pesticides and biotechnology series on the safety of manufactured nanomaterials. Number 6. List of manufactured nanomaterials and list of endpoints for phase one of the OECD testing programme. [Online 02 June 2008] 
Ono-Ogasawara, M., Kohyama, N., 1999. Evaulation of surface roughness of fibrous minerals by comparison of BET surface area and calculated one. Ann. Occup. Hyg. 43, 505511.

Oostingh, G.J., Schmittner, M., Ehart, A.K., Tischler, U., Duschl, A., 2008. A highthroughput screening method based on stably transformed human cells was used to determine the immunotoxic effects of fluoanthene and other PAHs. Toxicol. In Vitro 22, 1301-1310.

Ovrevik, J., Schwarze, P.E., 2005. Chemical composition and not only total surface area is important for the effects of ultrafine particles. Mutat. Res. 592, 119-137.

Poland, C.A., Duffin, R., Kinloch, I., Maynard, A., Wallace, W.A.H., Seaton, A., Stone, V., Brown, S., MacNee, W., Donaldson, K., 2008. Carbon nanotubes introduced into the abdominal cavity of mice show asbestos-like pathogenicity in a pilot study. Nat. Nanotech. 3 , 423-428.

Porter, D., Sriram, K., Wolfarth, M., Jefferson, A., Schwegler-Berry, D., Andrew, M.E., Castranova, V., 2008. A biocompatible medium for nanoparticle dispersion. Nanotoxicology 2, 144-154.

Post, M., van Golde, L.M., 1988. Metabolic and developmental aspects of the pulmonary surfactant system. Biochim. Biophys. Acta, 947, 249-286. 
Priya, B.R., Byrne, H.J., 2008. Investigation of sodium dodecyl benzene sulfonate assisted dispersion and debundling of single-wall carbon nanotubes. J. Phys. Chem. C. 112, 332-337.

Sager, T.M., Porter, D.W., Robinson, V.A., Lindsley, W.G., Schwegler-Berry, D.E., Castranova, V., 2007. Improved method to disperse nanoparticles for in vitro and in vivo investigation of toxicity. Nanotoxicology 1, 118-129.

Scarpelli, E.M., 1968. The surfactant system of the lung. Philadelphia, PA: Lea and Febiger.

Schürch, S., Gehr, P., Im Hof, V., Geiser, M., Green, F., 1990. Surfactant displaces particles toward the epithelium in airways and alveoli. Respir. Physiol. 80, 17-32.

Schürch, S., Bachofen, H., Goerke, J., Green, F., 1992., Surface properties of rat pulmonary surfactant studied with the captive bubble method: adsorption, hysteresis, stability. Biochim Biophys Acta 1103, 127-136.

Seaton, A., MacNee, W., Donaldson, K., Godden, D., 1995. Lancet 345, 176-178.

Shukla. A., Gulumian, M., Hei, T.K., Kamp, D., Rahman, Q., Mossman, B.T., 2003a. Multiple roles of oxidants in the pathogenesis of asbestos-induced diseases. Free Radical Biol. Med. 34, 1117-1129. 
Shukla, A., Ramos-Nino, M., Mossman, B., 2003b. Cell signalling and transcription factor activation by asbestos in lung injury and disease. Int. J. Biochem. Cell Biol. 35, 1198-1209.

Shvedova, A.A., Sager, T., Murray, A.R., Kisin, E., Porter, D.W., Leonard, S.S., SchweglerBerry, D., Robinson, V.A., Castranova, V., 2007. Critical issues in the evaluation of possible adverse pulmonary effects resulting from airborne nanoparticles. In: Monteiro-Riviere, N.A. and Tran, C.L. (Eds.), Nanotoxicology: Characterization, Dosing and Health Effects. Informa Healthcare, New York, London, pp. 225-236

Shvedova, A.A., Fabisiak, P., Kisin, E.R., Murray, A.R., Roberts, J.R., Tyurina, Y.Y., Antonini, J.M., Feng, W.H., Kommineni, C., Reynolds, J., Barchowsky, A., Castranova, V., Kagan, V.E., 2008. Sequential exposure to carbon nanotubes and bacteria enhances pulmonary inflammation and infectivity. Am. J. Respir. Cell Mol. Biol. 38, 579-590.

Simeonaova, P.P, Toriumi, W., Kommineni, C., 1997. Molecular regulation of IL-6 activation by asbestos in lung epithelial cells. J. Immunol. 150, 3921-3928.

Takizawa, H., 1998. Airway epithelial cells as regulators of airway inflammation (Review). Int. J. Mol. Med. 1, 367-378.

Utell, M.J., Frampton, M.W., 2000a. Acute health effects of ambient air pollution: the ultrafine particle hypothesis. J. Aerosol. Med. 13, 355-359. 
Utell, M.J., Frampton, M.W., 2000b. Toxicologic Methods: Controlled human exposures. Environ. Health Perspect. 108, 605-613.

Wallace, W.E., Keane, M.J., Hill, C.A., Xu, J., Ong, T., 1987. Mutagenicity of diesel exhaust particles and oil shale particles dispersed in lecithin surfactant. J. Toxicol. Environ. Health $21,163-171$.

Wallace, W.E., Keane, M.J., Murray, D.K., Chisholm, W.P., Maynard, A.D., Ong, T., 2006. Phospholipid lung surfactant and nanoparticle surface toxicity: Lessons from diesel soots and silicate dusts. J. Nanoparticle. Res. 9, 23-38

Wörle-Knirsch, J.M., Pulskamp, K., Krug, H.F., 2006. Oops they did it again! Carbon nanotubes hoax scientists in viability assays. Nano Lett. 6, 1261-68.

Yang, H.M., Antonini, J.M., Barger, M.W., Butterworth, L., Roberts, B.R., Ma, J.K., Castranova, V., Ma, J.Y., 2001. Diesel exhaust particles suppress macrophage function and slow down pulmonary clearance of Listeria monocytogenes in rats. Environ. Health Perspect. $109,515-521$.

Zhang, L.W., Zeng, L., Barron, A.R., Monteiro-Riviere, N.A., 2007. Biological interactions of functionalized single-wall carbon nanotubes in human epidermal keratinocytes. Int. J. Toxicol. 26, 103-113. 
Tables

Table 1: ELISA antibodies and supernatant dilutions

\begin{tabular}{|l|l|l|l|}
\hline Protein & Coating and detection AB & Highest Standard & Supernatant \\
IL-8 & $4 \mu \mathrm{l} / \mathrm{ml}$ & & dilution \\
\hline & BD Biosciences (Schwechat, & $10 \mu \mathrm{g} / \mathrm{ml}$ & $1: 5$ \\
\hline IL-6 & Austria) & & \\
& BD Biosciences (Schwechat, & $1 \mathrm{ng} / \mathrm{ml}$ & $1: 2$ \\
\hline TNF- $\alpha$ & Austria) & & $1: 1$ \\
\hline MCP-1 & $4 \mu \mathrm{l} / \mathrm{ml}$ & $10 \mu \mathrm{g} / \mathrm{ml}$ & $1: 2$ \\
\hline
\end{tabular}




\section{Figures}

Figure 1: A549 cells exposed to $12.5 \mu \mathrm{g} / \mathrm{ml}$ of HiPco SWCNT (a; b) or crocidolite asbestos (c; d) dispersed in A549 culture medium (a; c) or DPPC followed by addition to A549 culture medium $(b ; d)$.

Figure 2: Absorbance values of SWCNT dispersed in A549 medium ( $)$, DPPC followed by addition to A549 medium $(\triangle$ ), NHBE medium ( $\bigcirc$ ), DPPC followed by addition to NHBE medium $(\diamond)$

Figure 3: Cell viability of A549 cells following 48 hours exposure to HiPCo SWCNT (a; b) or crocidolite asbestos (c; d) dispersed in A549 medium or DPPC in the presence (b; d) or absence $(\mathrm{a} ; \mathrm{c})$ of stimulation with $10 \mathrm{ng} / \mathrm{ml} \mathrm{rh}-\mathrm{TNF}-\alpha$ as measured using the CellTiterBlue assay. * Denotes a significant difference from the control $(\mathrm{p} \leq 0.05)$.

Figure 4: Cell viability of NHBE cells following 48 hours exposure to HiPCo SWCNT (a) or crocidolite asbestos (b) dispersed in NHBE medium or DPPC in the presence or absence of stimulation with $10 \mathrm{ng} / \mathrm{ml} \mathrm{rh}-\mathrm{TNF}-\alpha$ as measured using the CellTiterBlue assay. * Denotes a significant difference from the control $(\mathrm{p} \leq 0.05)$. 
Figure 5: IL-8 Promoter activation of A549-IL8 reporter gene cells following 48 exposure to HiPco SWCNT with or without DPPC dispersion as measured by luciferase assay. a. no stimulation, b. stimulation with rh-TNF-a, c. stimulation with LPS-PA. * Denotes a significant difference from the control $(\mathrm{p} \leq 0.05)$.

Figure 6: IL-8 (a; b), IL-6 (c; d) and MCP-1 (e; f) protein release following 48h exposure to HiPco SWCNT dispersed in culture medium or DPPC of unstimulated A549 cells (a; c; d) and cells stimulated with rh-TNF-a $(b ; d ; f)$ as measured using ELISA. * Denotes a significant difference from the control $(\mathrm{p} \leq 0.05)$.

Figure 7: IL-8 (a; b) and IL-6 (c; d) protein release following 48h exposure to HiPco SWCNT dispersed in culture medium or DPPC by un-stimulated NHBE cells $(\mathrm{a} ; \mathrm{c})$ or cells stimulated by rh-TNF-a (b; d) as measured by ELISA. * Denotes a significant difference from the control $(\mathrm{p} \leq 0.05)$.

Figure 8: IL-8 (a; b), IL-6 (c; d) and MCP-1 (e; f) protein release following 48h exposure to Crocidolite asbestos dispersed in culture medium or DPPC of unstimulated A549 cells (a; c; d) and cells stimulated with rh-TNF-a (b; d; f) as measured using ELISA. * Denotes a significant difference from the control $(\mathrm{p} \leq 0.05)$. 
Figure 9: IL-8 (a; b) and IL-6 (c;+d) protein release following 48h exposure to Crocidolite asbestos dispersed in culture medium or DPPC by un-stimulated NHBE cells $(\mathrm{a} ; \mathrm{c})$ or cells stimulated by rh-TNF-a $(b ; d)$ as measured by ELISA. * Denotes a significant difference from the control $(\mathrm{p} \leq 0.05)$. 